\title{
Genetics of ascochyta blight resistance in chickpea
}

\author{
R. Bhardwaj · J. S. Sandhu · Livinder Kaur · \\ S. K. Gupta $\cdot$ P. M. Gaur $\cdot$ R. Varshney
}

Received: 30 April 2009/ Accepted: 6 August 2009/Published online: 3 September 2009

(C) Springer Science+Business Media B.V. 2009

\begin{abstract}
Genetics of resistance to ascochyta blight was studied using different generations of fifteen crosses of chickpea (Cicer arietinum L.). Six parents comprising two susceptible varieties GL 769, C 214 and four resistant lines GG 1267, GL 90168, GL 96010 and GL 98010 were used to develop one $\mathrm{S} \times \mathrm{S}$, eight $\mathrm{S} \times \mathrm{R}$ and six $\mathrm{R} \times \mathrm{R}$ crosses and some of the back crosses and $\mathrm{F}_{3}$ generations were developed. Field screening technique was used to evaluate the different generations for disease reaction using mixture of ten prevalent isolates $\left(a b_{1}-a_{10}\right)$ of ascochyta blight (Ascochyta rabiei). Inheritance study showed digenic recessive control of resistance in the cross GL $769 \times \mathrm{C} 214$, whereas monogenic recessive control of resistance was found in the crosses GL $769 \times$ GL 98010 and C $214 \times$ GL 98010. Digenic dominant and recessive control of resistance was found in the crosses GL $769 \times$ GG 1267 and C $214 \times$ GG 1267 while the crosses GL $769 \times$ GL 90168 and C $214 \times$ GL 96010 showed the monogenic dominant control of resistance. Trigenic dominant and recessive control of resistance was observed in the crosses GL $769 \times$ GL 96010 and C
\end{abstract}

R. Bhardwaj ( $₫)$ · J. S. Sandhu · L. Kaur Department of Plant Breeding and Genetics, Punjab Agricultural University, Ludhiana 14004, India e-mail: ruchipau@gmail.com

S. K. Gupta · P. M. Gaur · R. Varshney International Crop Research Institute for Semi-Arid Tropics, Pattencheru, India
$214 \times$ GL 90168. Allelic relationship studies showed that three resistant parents viz., GG 1267, GL 96010 and GL 90168 possessed allelic single dominant gene for resistance. Besides, GG 1267 possessed two minor recessive genes for resistance, one of them was allelic to the minor recessive gene possessed by GL 90168 and other with GL 96010. The resistant parents GL 90168 and GL 96010 possessed non-allelic minor gene for resistance. The resistant parent GL 98010 possessed two minor recessive genes for resistance which were allelic to respective single recessive gene for resistance possessed by the susceptible parents GL 769 and C 214. The susceptible parents GL 769 and C 214 also possessed single independent inhibitory dominant susceptibility gene. The inhibitory gene was epistatic to the corresponding recessive gene for resistance.

Keywords Ascochyta blight - Ascochyta rabiei . Chickpea - Genetics of resistance

\section{Introduction}

Chickpea (Cicer arietinum L.) is the third most important food legume crop grown worldwide after dry beans and field peas. India ranks first in chickpea production and alone contributes about $65 \%$ in global production (FAO 2007). However, there is not much 
improvement in the crop productivity $(840 \mathrm{Kg} / \mathrm{ha})$ for the last several years. The main reasons for low productivity are susceptibility of chickpea cultivars to biotic and abiotic stresses which reduces yield and yield stability. Among the biotic stresses, the necrotrophic foliar fungal disease ascochyta blight caused by Ascochyta rabiei (Pass.) Labrousse, is the most severe yield reducing disease of north-west India. The occurrence of ascochyta blight has been reported in more than 40 countries of the world and has become one of the major constraints in chickpea cultivation. In India, the severity of disease was noticed in form of epidemics during 1981-83 that caused 100\% crop loss (Singh et al. 1982, 1984). Subsequently, increasing resistance to ascochyta blight to increase yield is the predominant aim of chickpea breeders through out the world. Thus, it is and Kabbabeh 1985; Baaya et al. 2004). It has aroused the interest to study the genetics of resistance and their allelism against the isolates of Ascochyta rabiei of the region in chickpea and its details are presented in this article.

\section{Materials and methods}

\section{Plant materials}

Two released cultivars of chickpea, GL 769 and C 214 , susceptible to ascochyta blight and four advance breeding lines viz; GG 1267, GL 90168, GL 96010 and GL 98010 as resistant parents were selected for the study. The detailed information of chickpea genotypes used in the study is given below:

\begin{tabular}{|c|c|c|c|c|c|}
\hline Genotype & Pedigree & $\begin{array}{l}\text { Disease } \\
\text { score }^{\mathrm{a}}\end{array}$ & $\begin{array}{l}\text { Disease } \\
\text { reaction }\end{array}$ & Type & Remarks \\
\hline GL 769 & H $223 \times$ L 168 & 9 & Susceptible & Desi & $\begin{array}{l}\text { Widely adapted chickpea variety } \\
\text { for irrigated and rainfed conditions }\end{array}$ \\
\hline C 214 & G-24 × (G $24 \times$ IP-58) & 9 & Susceptible & Desi & $\begin{array}{l}\text { Widely adapted chickpea variety } \\
\text { for rainfed conditions }\end{array}$ \\
\hline GG 1267 & FG $190 \times$ PBG 1 & 2 & Resistant & Desi & High yielding and tall advance breeding line \\
\hline GL 90168 & GL $84091 \times$ GL 84213 & 2 & Resistant & Desi & $\begin{array}{l}\text { High yielding advance breeding line } \\
\text { and medium seed size }\end{array}$ \\
\hline GL 96010 & GL $769 \times$ GL 86143 & 2 & Resistant & Desi & $\begin{array}{l}\text { High yielding advance breeding line } \\
\text { and medium seed size }\end{array}$ \\
\hline GL 98010 & PBG $1 \times$ ICC-1069 & 2 & Resistant & Desi & $\begin{array}{l}\text { High yielding advance breeding line } \\
\text { and medium seed size }\end{array}$ \\
\hline
\end{tabular}

${ }^{a}$ Disease score (1-9 Scale); $1=$ highly resistant, $3=$ resistant, $5=$ moderately resistant, $6=$ moderately susceptible and $9=$ highly susceptible

imperative to develop the resistant cultivars and to understand the genetics of resistance to the pathogen. The studies made in the past revealed that ascochyta blight resistance is controlled by single gene (Tewari and Pandey 1985), two genes (Dey and Singh 1993), two dominant and one recessive gene (Tewari and Pandey 1986) and polygenic (Flandez-Galvez et al. 2003; Cho et al. 2004). The further study of genetics of resistance to ascochyta blight will help in the identification of resistance gene/s and their allelism for diversity of resistance genes. On the other hand, the pathogen is also genetically variable as a number of isolates have been reported (Singh 1990; Reddy
All the six parents were sown in crop season 200405 at the research farm of Punjab Agricultural University (PAU), Ludhiana, India and crosses among the parents were attempted to develop $15 \mathrm{~F}_{1 \mathrm{~s}}$ involving eight susceptible $(\mathrm{S}) \times$ resistant $(\mathrm{R})$ crosses, six $\mathrm{R} \times \mathrm{R}$ crosses and one $\mathrm{S} \times \mathrm{S}$ cross. In the following crop season 2005-06 all $15 \mathrm{~F}_{1} \mathrm{~s}$ were sown to advance the generation and also used to develop the $\mathrm{BC}_{1} \mathrm{~s}$ and $\mathrm{BC}_{2} \mathrm{~s}$ of seven crosses (Table 3). The off-season nursery (summer 2006) at Keylong, Himachal Pradesh, India, was used to advance $\mathrm{F}_{2}$ population of two crosses to $\mathrm{F}_{3}$ generation and their single plants were harvested, separately. The different generations of all 
the crosses were sown in the ascochyta blight screening nursery in the crop season of 2006-07 at the research farm of PAU, Ludhiana. One row of each parent, two rows of $\mathrm{F}_{1 \mathrm{~s}}$, three rows of $\mathrm{BC}_{1}$ and $\mathrm{BC}_{2}$ and 40 rows of $F_{2}$ of each of the fourteen crosses were sown. In the fifteenth cross involving susceptible $\times$ susceptible parents, viz., C $214 \times$ GL 769, one row of each parent, two rows of $F_{1}$ and 20 rows of $\mathrm{F}_{2}$ were sown. One hundred and thirty-seven single plant $F_{3}$ progenies of the cross GL $769 \times$ GL 90168 and one hundred and sixty-five single plant progenies of the cross C $214 \times$ GL 96010 were also planted. In each row of $2 \mathrm{~m}$ length, 11 plants were accommodated. The plant to plant spacing of $20 \mathrm{~cm}$ and row to row spacing of $40 \mathrm{~cm}$ was maintained. The check variety L 550, susceptible to ascochyta blight was planted as an indicator-cum-infestor row after every 8 rows of test material. The recommended package of practices was followed to raise the crop.

\section{Screening of the material}

The field screening technique of Gurha et al. (2003) was used to develop the disease and evaluation of different generations for disease reaction. The experimental crop was artificially inoculated by spraying the mixture of ten prevalent isolates $a b_{1}-a b_{10}$ of the pathogen (Ascochyta rabiei) of the region. The inoculation was done on February 9, 2007 in the evening and prior to inoculation, the field was irrigated. The inoculum suspension was prepared in the Pulse Pathology Laboratory at PAU. The spore suspension strength of $4 \times 10^{4}$ spores $/ \mathrm{ml}$ was used. The inoculation was done with knap-sack sprayer. The epiphytotic conditions were created with the help of perfo-sprayer system to maintain the relative humidity beyond 85 per cent and temperature around $25^{\circ} \mathrm{C}$. Mild temperatures $\left(20-25^{\circ} \mathrm{C}\right)$ and high relative humidity (85-95\%) is the most congenial conditions for the quicker development of the disease. The perfo-sprayer system was run during day time from 10:00-16:00 hours at an interval of $1 \mathrm{~h}$ for 21 days to maintain the relative humidity. The disease symptoms started appearing after 10-15 days of inoculation.

Data collection and analysis

After 3 weeks of inoculation i.e. on March 1, 2007, individual plants were scored for disease reaction on
1-9 scale where, $1=$ highly resistant, $3=$ resistant, $5=$ moderately resistant, $6=$ moderately susceptible and $9=$ highly susceptible (Singh and Sharma 1998). The assessment of the disease per plant was obtained by observing the intensity of lesions present on the whole plant. The plants with disease rating $\leq 5$ were considered as resistant and above 5 as susceptible. Based on disease reaction, plants of each cross were classified into two classes i.e. resistant and susceptible. The single plant $\mathrm{F}_{3}$ progenies were scored as segregating, homozygous resistant (HR) and homozygous susceptible (HS) based on the disease reaction of progenies. Data were fit into different genetic ratios to find out the best fit ratio in order to know the genetics of resistance to ascochyta blight. Chi-square $\left(\chi^{2}\right)$ test was applied to fit the appropriate genetic ratio for the estimation of number of gene (s) governing resistance and also to find out allelic relationship among resistance genes.

\section{Results and discussion}

The perusal of results of different generations' viz., $\mathrm{P}_{1}, \mathrm{P}_{2}, \mathrm{~F}_{1}, \mathrm{~F}_{2}, \mathrm{~F}_{3}, \mathrm{BC}_{1}$ and $\mathrm{BC}_{2}$ of different crosses are presented in Tables 1, 2 and 3. For convenience, results are discussed under three sub-heads.

Susceptible $\times$ Susceptible cross

The parents (GL 769, C 214) and their $F_{1 \mathrm{~s}}$ exhibited susceptible reaction under epiphytotic conditions. However, $F_{2}$ generation segregated in a digenic ratio of $15 \mathrm{~S}: 1 \mathrm{R}$. It indicated complementation of two recessive resistance genes and each parent possessed one gene for resistance. These genes could be termed as minor genes for resistance as they individually were so weak to exhibit the resistant reaction. Furthermore, the resistant reaction exhibited only when both the recessive genes were in homozygous condition in an individual plant. It inferred that susceptible parents also possessed independent inhibitory dominant gene which suppressed the resistant reaction when single recessive resistance gene in homozygous condition in the respective parents and both the recessive resistance genes in the heterozygous conditions. The dominance of susceptibility over ascochyta blight resistance has also been reported by Danehloueipour et al. (2007). 
Table 1 Reaction of parents, $F_{1}, F_{2}$ and $F_{3}$ generations to ascochyta blight in chickpea

\begin{tabular}{|c|c|c|c|c|c|c|c|c|c|c|c|c|c|c|}
\hline \multirow[t]{2}{*}{ Cross } & \multicolumn{2}{|c|}{ Parents } & \multirow[t]{2}{*}{$\mathrm{F}_{1}$} & \multicolumn{5}{|l|}{$\mathrm{F}_{2}$} & \multicolumn{6}{|l|}{$\mathrm{F}_{3}$} \\
\hline & $\mathrm{P}_{1}$ & $\overline{P_{2}}$ & & $R$ & $S$ & $\begin{array}{l}\text { Expected } \\
\text { ratio (R:S) }\end{array}$ & $\chi^{2}$ & $P$-value & $\overline{\mathrm{HR}}$ & Seg & HS & $\begin{array}{l}\text { Expected } \\
\text { ratio }\end{array}$ & $\chi^{2}$ & $P$-value \\
\hline GL769 $\times$ C214 & $\mathrm{S}$ & $\mathrm{S}$ & $\mathrm{S}$ & 9 & 132 & $1: 15$ & 3.2 & $0.1-0.05$ & - & - & - & - & - & - \\
\hline GL769 × GG1267 & $\mathrm{S}$ & $\mathrm{R}$ & $\mathrm{R}$ & 308 & 71 & $13: 3$ & 1.42 & $0.3-0.2$ & - & - & - & - & - & - \\
\hline GL769 × GL90168 & $\mathrm{S}$ & $\mathrm{R}$ & $\mathrm{R}$ & 264 & 91 & $3: 1$ & 1.2 & $0.2-0.10$ & 38 & 73 & 26 & $1: 2: 1$ & 2.9 & $0.3-0.2$ \\
\hline GL769 × GL96010 & $\mathrm{S}$ & $\mathrm{R}$ & $\mathrm{R}$ & 297 & 100 & $49: 15$ & 0.691 & $0.5-0.3$ & - & - & - & - & - & - \\
\hline GL769 × GL98010 & $\mathrm{S}$ & $\mathrm{R}$ & $\mathrm{S}$ & 99 & 250 & $1: 3$ & 2.05 & $0.2-0.10$ & - & - & - & - & - & - \\
\hline C214 × GG1267 & $\mathrm{S}$ & $\mathrm{R}$ & $\mathrm{R}$ & 318 & 81 & $13: 3$ & 0.59 & $0.5-0.30$ & - & - & - & - & - & - \\
\hline C214 × GL90168 & $S$ & $\mathrm{R}$ & $\mathrm{R}$ & 232 & 67 & $49: 15$ & 1.2 & $0.3-0.20$ & - & - & - & - & - & - \\
\hline C214 × GL96010 & $\mathrm{S}$ & $\mathrm{R}$ & $\mathrm{R}$ & 282 & 104 & $3: 1$ & 0.88 & $0.5-0.3$ & 34 & 90 & 41 & $1: 2: 1$ & 1.8 & $0.5-0.3$ \\
\hline C214 × GL98010 & $\mathrm{S}$ & $\mathrm{R}$ & $\mathrm{S}$ & 110 & 275 & $1: 3$ & 2.74 & $0.1-0.05$ & - & - & - & - & - & - \\
\hline
\end{tabular}

Table 2 Reaction of parents, $F_{1}$ and $F_{2}$ generations of resistant $\times$ resistant crosses to ascochyta blight in chickpea

\begin{tabular}{|c|c|c|c|c|c|c|c|c|}
\hline \multirow[t]{2}{*}{ Cross } & \multicolumn{2}{|c|}{ Parents } & \multirow[t]{2}{*}{$\mathrm{F}_{1}$} & \multicolumn{5}{|l|}{$\mathrm{F}_{2}$} \\
\hline & $\mathrm{P}_{1}$ & $\mathrm{P}_{2}$ & & $R$ & $S$ & Expected ratio (R:S) & $\chi^{2}$ & $P$-value \\
\hline GG1267 × GL90168 & $\mathrm{R}$ & $\mathrm{R}$ & $\mathrm{R}$ & 365 & 0 & No segregation & - & - \\
\hline GG1267 × GL96010 & $\mathrm{R}$ & $\mathrm{R}$ & $\mathrm{R}$ & 333 & 0 & No segregation & - & - \\
\hline GG1267 × GL98010 & $\mathrm{R}$ & $\mathrm{R}$ & $\mathrm{R}$ & 338 & 0 & No segregation & - & - \\
\hline GL90168 × GL96010 & $\mathrm{R}$ & $\mathrm{R}$ & $\mathrm{R}$ & 395 & 0 & No segregation & - & - \\
\hline GL90168 × GL98010 & $\mathrm{R}$ & $\mathrm{R}$ & $\mathrm{R}$ & 309 & 80 & $13: 3$ & 0.821 & $0.5-0.3$ \\
\hline GL96010 × GL98010 & $\mathrm{R}$ & $\mathrm{R}$ & $\mathrm{R}$ & 390 & 0 & No segregation & - & - \\
\hline
\end{tabular}

Susceptible $\times$ Resistant crosses

Eight crosses involving resistant $\times$ susceptible parents were studied. The crosses viz., GL $769 \times$ GG 1267 and C $214 \times$ GG 1267 exhibited that resistance was dominant over susceptibility in both $F_{1 s}$. The $F_{2}$ population of these crosses segregated into 13R:3S genetic ratio indicating digenic (one dominant and one recessive gene) control of ascochyta blight resistance. Dominant control of ascochyta blight resistance was also reported by Dey and Singh (1993) and Mahendra et al. (1999). The $\mathrm{BC}_{1}$ generation of the cross GL $769 \times$ GG 1267 , showed as expected 1R:1S $\left(\chi^{2}=0.66\right)$ segregation and $\mathrm{BC}_{2}$ generation showed no segregation as all the plants were resistant. These results substantiated that the resistant parent GG 1267 possessed one major dominant gene and two minor recessive genes for resistance. The minor resistance genes possessed by GG 1267 might be common with recessive gene for resistance possessed by either of the susceptible parents. However, the $\mathrm{BC}_{1}$ and $\mathrm{BC}_{2}$ generations of other cross were not studied.

The $\mathrm{F}_{1}$ 's of the crosses GL $769 \times$ GL 90168 and C $214 \times$ GL 90168 exhibited resistant reaction indicating dominance of resistance over susceptibility. The $F_{2}$ population of the cross GL $769 \times$ GL 90168 segregated with a good fit to $3 \mathrm{R}: 1 \mathrm{~S}\left(\chi^{2}=1.2\right)$ and the $\mathrm{F}_{3}$ single plant progenies of this cross segregated in $1 \mathrm{HR}: 2 \mathrm{Seg}: 1 \mathrm{HS}$ ratio $\left(\chi^{2}=2.90\right)$. It confirmed one dominant resistance gene governed the resistant reaction in this cross. Furthermore, the $\mathrm{BC}_{1}$ generation of this cross exhibited 1R:1S $\left(\chi^{2}=0.28\right)$ segregation ratio whereas $\mathrm{BC}_{2}$ generation did not show any segregation as all the plants were resistant as expected for the monogenic dominant control of resistance. In other cross C $214 \times$ GL 90168, 49R:15S segregation pattern was observed in the $F_{2}$ generation which showed trigenic control of resistance. This revealed that at least one gene for resistance was dominant as $\mathrm{F}_{1}$ was resistant and other two resistance genes were recessive. Thus, it is 
Table 3 Reaction of $\mathrm{BC}_{1}$ and $\mathrm{BC}_{2}$ generations to ascochyta blight in chickpea

\begin{tabular}{|c|c|c|c|c|c|}
\hline Cross & $R$ & $S$ & Expected ratio (R:S) & $\chi^{2}$ & $P$-value \\
\hline \multicolumn{6}{|l|}{$\mathrm{BC}_{1}$} \\
\hline GL769 $\times$ GG1267 & 10 & 14 & $1: 1$ & 0.66 & $0.5-0.3$ \\
\hline GL769 $\times$ GL90168 & 6 & 8 & $1: 1$ & 0.28 & $0.95-0.5$ \\
\hline C214 × GL96010 & 13 & 13 & $1: 1$ & 0.52 & $0.5-0.3$ \\
\hline C214 × GL98010 & 0 & 32 & No segregation & - & - \\
\hline GG1267 × GL90168 & 28 & 0 & No segregation & - & - \\
\hline GL96010 × GL98010 & 19 & 0 & No segregation & - & - \\
\hline GL90168 × GL96010 & 7 & 0 & No segregation & - & - \\
\hline \multicolumn{6}{|l|}{$\mathrm{BC}_{2}$} \\
\hline GL769 $\times$ GG1267 & 25 & 0 & No segregation & - & - \\
\hline GL769 $\times$ GL90168 & 1 & 0 & No segregation & - & - \\
\hline C214 × GL96010 & 30 & 0 & No segregation & - & - \\
\hline C214 × GL98010 & 8 & 6 & $1: 1$ & 1.58 & $0.5-.01$ \\
\hline GG1267 × GL90168 & 2 & 0 & No segregation & - & - \\
\hline GL96010 × GL98010 & 10 & 6 & $3: 1$ & 0.99 & $0.1-.05$ \\
\hline GL90168 $\times$ GL96010 & 8 & 0 & No segregation & - & - \\
\hline
\end{tabular}

evident that resistant parent GL 90168 possessed one dominant and one recessive gene for resistance, and second recessive resistance gene was contributed by the susceptible parent C 214. Diverse dominant and recessive gene controlling resistance has been reported by earlier workers (Verma et al. 1991; Dey and Singh 1993).

Two crosses GL $769 \times$ GL 96010 and C $214 \times$ GL 96010, involving the resistant parent GL 96010 were studied. Their $\mathrm{F}_{1}$ plants exhibited resistant reaction indicating resistance was dominant over susceptibility. The $\mathrm{F}_{2}$ generation of the cross GL $769 \times$ GL 96010 segregated into 49R:15S $\left(\chi^{2}=0.691\right)$ while other cross C $214 \times$ GL 96010 showed 3R:1S segregation ratio $\left(\chi^{2}=0.88\right)$. The first cross showed trigenic and the other cross exhibited monogenic control of resistance. These observations clearly indicated that one dominant and two recessive genes governed the resistance reaction in cross GL $769 \times$ GL 96010 . The $\mathrm{BC}_{1}, \mathrm{BC}_{2}$ and $\mathrm{F}_{3}$ generations of the cross $\mathrm{C}$ $214 \times$ GL 96010 confirmed one dominant gene control of resistance. It could be inferred that the resistant parent GL 96010 possessed one dominant gene for resistance and at the same time minor gene/s for resistance. However, the minor gene/s could not express in the presence of dominant resistance gene. It also indicated that one of the recessive resistance gene possessed by the parent GL 96010 was same with that of the recessive resistance gene of the susceptible parent C 214. However, the other susceptible parent GL 769 of the cross GL $769 \times$ GL 96010, possessed different recessive resistance gene. Thus, the resistant parent GL 96010 possessed one dominant gene and one recessive gene for resistance and third recessive resistance gene was shared by the susceptible parent GL 769 to support the trigenic segregation. It also showed that independent inhibitory dominant gene present in both the susceptible parents interfere in the segregation pattern.

The $\mathrm{F}_{1}$ hybrids of the crosses GL $769 \times$ GL 98010 and C $214 \times$ GL 98010 were susceptible, indicating resistance was recessive and susceptibility was dominant in these two crosses. The $F_{2}$ generations of both the crosses showed 1R:3S genetic ratio which inferred monogenic recessive control of resistance. The $\mathrm{BC}_{1}$ and $\mathrm{BC}_{2}$ generations of the cross $\mathrm{C}$ $214 \times$ GL 98010 confirmed the monogenic recessive control of resistance. However, the $\mathrm{BC}_{1}$ and $\mathrm{BC}_{2}$ generations of other cross were not studied. The resistant parent GL 98010 probably possessed two minor genes for resistance as one of them was common with either of the susceptible parents. Furthermore, presence of two minor genes did not affect the segregation pattern in $\mathrm{F}_{2}$ and it remained as same for one recessive gene segregation due to the presence of inhibitory dominant gene of the 
susceptible parents. Recessive genes controlling the resistance have been reported by several workers (Singh and Reddy 1983; Tewari and Pandey 1985; Danehloueipour et al. 2007). Thus, these results confirmed that the resistant parent GL 98010 possessed two minor recessive genes for resistance, however, the segregation pattern was monogenic.

Resistant $\times$ Resistant crosses

The allelism of resistance genes were studied in six $\mathrm{R} \times \mathrm{R}$ crosses. The results are presented crosswise.

In the first cross, involving resistant parents GG 1267 and GL 90168, all $F_{1}$ plants were resistant and $\mathrm{F}_{2}$ population did not show segregation as all the plants were resistant. This inferred that the resistance gene was allelic in both the parents and dominant in nature. Allelic nature of resistance gene was further confirmed from $\mathrm{BC}_{1}$ and $\mathrm{BC}_{2}$ generations segregation pattern. However, the $\mathrm{S} \times \mathrm{R}$ crosses involving these two resistant parents showed different segregation patterns in $F_{2}$. The $F_{2}$ populations of the susceptible parents with resistant parent GG 1267 showed 13R:3S segregation ratio while other resistant parent GL 90168 showed segregation ratios with GL 769, 3R:1S and with C 214, 49R:15S. The varying segregation ratios clearly indicated that the resistant parents were allelic for the dominant resistance gene but resistant parent GL 90168 also possessed recessive gene for resistance which was non-allelic in nature. The non-allelic minor gene for resistance led to different segregation ratios in $\mathrm{F}_{2}$ with susceptible parents GL 769 and C 214.

The $F_{1}$ plants of the cross involving resistant parents GG 1267 and GL 96010 showed resistant reaction under epiphytotic conditions and indicated dominance of resistance. The $\mathrm{F}_{2}$ population exhibited resistant reaction. It revealed that resistance genes governing the resistant reaction were same in both the parents. However, the $\mathrm{S} \times \mathrm{R}$ crosses involving $\mathrm{GG}$ 1267 and GL 96010 as a male parent with susceptible female parents, showed different segregation ratios in $\mathrm{F}_{2}$. It evidenced that resistant parents were allelic for the dominant gene while non-allelic for at least one minor recessive gene for resistance.

The $F_{1}$ plants of the cross GG $1267 \times$ GL 98010 showed resistant reaction which indicated the dominance of resistance. All the plants were resistant in the $F_{2}$ population. However, the resistant parent GG
1267 in crosses with both the susceptible parents GL 769 and $C 214$ showed dominant control of resistance whereas, the $\mathrm{F}_{2}$ segregation pattern with other resistant parent GL 98010 was monogenic recessive indicated that both the resistant parents were nonallelic for the dominant gene for resistance.

Dominance of resistance was noticed from $\mathrm{F}_{1}$ plants of the cross involving resistant parents GL 90168 and GL 96010. All the plants of $F_{2}$ population were resistant. Furthermore, the $\mathrm{BC}_{1}$ and $\mathrm{BC}_{2}$ generations of this cross did not show any segregation for resistance and susceptibility. However, different genetic ratios in $F_{2}$ generations were observed from the crosses between these resistant parents and common susceptible parents. It revealed that the resistant parents possessed allelic dominant resistance gene and non-allelic minor recessive resistance gene/s. The resistant parent GL 90168 in cross with GL 769 showed monogenic dominant control of resistance whereas with C 214, it showed the trigenic control of resistance with at least one dominant gene and two minor genes governing resistance in this cross. While other resistant parent GL 96010 showed trigenic control of resistance with susceptible parent GL 769 and dominant monogenic with $\mathrm{C} 214$ in $\mathrm{F}_{2}$ generation.

The $\mathrm{F}_{1}$ individuals of the cross GL $96010 \times \mathrm{GL}$ 98010 were resistant and $F_{2}$ population showed no segregation as all the plants were resistant. Furthermore, the $\mathrm{BC}_{1}$ generation did not show any segregation for resistance but $\mathrm{BC}_{2}$ generation showed $3 \mathrm{R}: 1 \mathrm{~S}$ segregation ratio, which evidenced that both the parents were non-allelic for the resistance gene. It could be inferred that dominant resistance gene was non-allelic and recessive resistance genes were allelic in two resistant parents involved in the cross. It indicated that one dominant gene governs the resistance in the parent GL 96010 and minor resistance genes might be same in both the parents. These observations confirmed with their pattern of segregation for resistance with common susceptible parents, GL769 and C 214.

The $F_{1}$ plants of the cross GL $90168 \times$ GL 98010 showed resistant reaction. Their $\mathrm{F}_{2}$ population segregated into 13R:3S ratio indicating that resistant parents were non-allelic for the genes of resistance. These finding were further supported with results obtained with common susceptible parents. The results inferred that resistant parent GL 90168 possessed one dominant gene and one recessive gene 
Table 4 The proposed genotypes of parents and nature of resistance gene/s to ascochyta blight in chickpea

\begin{tabular}{lll}
\hline Parent & Genotype proposed & Nature of resistance gene/s \\
\hline GL769 & aaBBcc & Recessive \\
C214 & AAbbcc & Recessive \\
GG1267 & aabbCC & Dominant and recessive \\
GL90168 & aaBBCC & Dominant and recessive \\
GL96010 & AAbbCC & Dominant and recessive \\
GL98010 & aabbcc & Recessive \\
\hline
\end{tabular}

for resistance while GL 98010 possessed two recessive genes for resistance. Thus, dominant gene for resistance was non-allelic and recessive gene for resistance may be allelic with one of the recessive gene for resistance possessed by resistant parent GL 98010 .

Genetic studies inferred that in all the fifteen crosses studied, three resistant parents GG 1267, GL 96010 and GL 90168 possessed one dominant gene for resistance besides possessing minor recessive gene(s) for resistance. The fourth resistant parent GL 98010 possessed two minor recessive genes for resistance while segregation pattern was monogenic. The susceptible parents GL 769 and C 214 also possessed one diverse minor recessive gene for resistance in addition to inhibitory dominant gene for susceptibility. The inhibitory gene was epistatic to corresponding recessive gene for resistance. On the basis of these results, the genotype and nature of resistance gene/s of all the six parents are proposed as given in Table 4.

The information of genetics of resistance generated from this study is very useful as diverse genes for resistance were identified against the prevalent isolates of ascochyta blight of the region. The resistance genes would be used to develop the durable resistant cultivars of chickpea through pyramiding of these genes.

\section{References}

Baaya BS, Udupa M, Baum M, Malhotra RS, Kabbabeh S (2004) Pathogenic variability in Syrian Isolates of Ascochyta rabiei. In: Proceedings of the 5th European conference on grain legumes for the benefit of agriculture, Nutrition and the Environment. Dijon 7-11 June 2004. (European Association for Grain Legume Research: Dijon, France)

Cho S, Chen W, Muehlbauer FJ (2004) Pathotype specific genetic factors in chickpea (Cicer arietinum L.) for quantitative resistance to ascochyta blight. Theor Appl Genet 109:733-739

Danehloueipour NG, Yan G, Clarke HJ, Siddique KHM (2007) Diallel analysis reveal the genetic control of resistance to Ascochyta blight in diverse chickpea and wild Cicer species. Euphytica 154:195-205

Dey SK, Singh G (1993) Resistance to Ascochyta blight in chickpea-Genetic basis. Euphytica 68:147-153

FAO (2007) Statistical database. At http://www.fao.org

Flandez-Galvez H, Ford R, Pang ECK, Taylor PWJ (2003) An intraspecific linkage map of the chickpea (Cicer arietinum L.) genome based on sequence tagged microsatellite site and resistant gene analog markers. Theor Appl Genet 106:1447-1456

Gurha SN, Singh G, Sharma YR (2003) Diseases of chickpea and their management. In: Ali M, Kumar S, Singh NB (eds) Chickpea research in India. Indian Institute of Pulses Research, Kanpur (India), pp 195-227

Mahendra P, Pandia RS, Kumar J, Singh B (1999) Genetics of resistance to Ascochyta blight in chickpea. Indian Phytopath 52:403-407

Reddy MV, Kabbabeh S (1985) Pathogenic variability in Ascochyta rabiei (Pass.) Lab. In Syria and Lebanon. Phytopath Mediterr 24:265-266

Singh G (1990) Identification and designation of physiologic races of Ascochyta rabiei in India. Indian Phytopath 43:48-52

Singh KB, Reddy MV (1983) Inheritance of resistance to Ascochyta blight in chickpea. Crop Sci 23:9-10

Singh G, Singh K, Kapoor S (1982) Screening for sources of resistance to Ascochyta blight of chickpea. Int Chickpea Newsl 6:15-17

Singh G, Verma MM, Gill AS, Sandhu TS, Brar HS, Sra SS, Kapoor S (1984) Screening of gram varieties against Ascochyta blight. Crop Improv 11:153-154

Tewari SK, Pandey MP (1985) Allelic relationship between genes for resistance to ascochyta blight in chickpea. Int Chickpea Newsl 12:13-15

Tewari SK, Pandey MP (1986) Genetics of resistance to Ascochyta blight in chickpea (Cicer arietinum L.). Euphytica 35:211-215

Verma MM, Singh G, Sandhu TS, Brar HS, Singh K, Bhullar BS (1981) Sources of resistance to gram blight and gray mould. Int Chickpea Newsl 4:14-16

Verma MM, Sandhu JS, Singh G, Kaur L, Brar HS (1991) Genetics of resistance to ascochyta blight in chickpea. In: Proceedings of golden jubilee celebration symposium on grain legume Feb 9-11, 1991 IARI, New Delhi, India, pp 261-73 